\title{
A Shoulder Mass Revealing a Metastatic Prostate Cancer
}

\author{
Kanta Ka ${ }^{*}$, Mohamed Jalloh ${ }^{2,3 *}$, Babacar Sine ${ }^{3,4}$, Oumar Gaye ${ }^{2}$, Awa Sadikh Badiane ${ }^{1}$, \\ Ibrahima Thiam1, Mamadou Moustapha Dieng3, Papa Macoumba Gaye ${ }^{1,3}$
}

\author{
${ }^{1}$ Radiotherapy Department, Centre Hospitalier National Universitaire Dalal Jamm, Guédiawaye, Senegal \\ ${ }^{2}$ Urology Department, Hôpital Général Idrissa Pouye, Grand Yoff, Senegal \\ ${ }^{3}$ Cheikh Anta Diop University, Dakar, Senegal \\ ${ }^{4}$ Urology Department, Centre Hospitalier Universitaire Aristide Le Dantec, Dakar, Senegal \\ Email: *ka.kanta04@gmail.com, ^kanta.ka@gustaveroussy.fr, *jmohamed60@yahoo.fr, oumargaye-uro@outlook.fr, \\ awasadikh@gmail.com, ibathiam29@gmail.com, papesine@yahoo.fr, macoumba.gaye@gmail.com, \\ moustaphamamadou@gmail.com
}

How to cite this paper: Ka, K., Jalloh, M., Sine, B., Gaye, O., Badiane, A.S., Thiam, I., Dieng, M.M. and Gaye, P.M. (2021) A Shoulder Mass Revealing a Metastatic Prostate Cancer. Case Reports in Clinical Medicine, 10, 133-139.

https://doi.org/10.4236/crcm.2021.104016

Received: March 12, 2021

Accepted: April 24, 2021

Published: April 27, 2021

Copyright $\odot 2021$ by author(s) and Scientific Research Publishing Inc. This work is licensed under the Creative Commons Attribution International License (CC BY 4.0).

http://creativecommons.org/licenses/by/4.0/

Open Access

\begin{abstract}
Introduction: A shoulder mass revealing metastatic prostate cancer is very rare. We report a case of metastatic prostate cancer diagnosed on a shoulder mass and treated with analgesic radiotherapy and chemotherapy and androgen deprivation therapy (ADT). Observations: A 66 years old patient was referred for a painful right shoulder mass whose biopsy and pathological examination found a Gleason $8(4+4)$ moderately differentiated adenocarcinoma. The PSA level was $508.52 \mathrm{ng} / \mathrm{ml}$. The patient was treated with analgesic radiotherapy on the right shoulder and chemo-hormonal therapy. At 2 years follow-up, the disease was well controlled. Conclusion: A shoulder mass revealing metastatic prostate cancer is not common. Local treatment of the symptomatic metastasis while continuing chemotherapy and ADT improves the quality of life.
\end{abstract}

\section{Keywords}

Shoulder, Prostate, Cancer, Metastasis

\section{Introduction}

Metastasis found at the time of cancer diagnosis accounts for $4 \%$ of prostate cancer diagnosis [1]. It is often a more aggressive disease compared to prostate cancer which progresses with metachronous metastases, both in terms of life expectancy and the duration of response to androgen deprivation therapy (ADT) [2]. The diagnosis of localized forms has become increasingly important, so are 
the forms presenting with metastasis at initial diagnosis, owing to the development of diagnostic methods, mostly imaging [3]. Bone is the third most common metastatic site after the lung and liver [4]. Treatment is based on ADT combined with second-generation hormone therapy or docetaxel chemotherapy [5]. Some studies show a benefit of local treatment in selected presenting metastatic and hormone-sensitive prostate cancer [6] [7] [8]. It should be noted that metastases are a major cause of morbidity and affect the quality of life in $70 \%$ of cases; particularly because of the pain they cause [9]. Metastases can be treated with various radiotherapy regimens [10] [11] [12]. We report this case of the prostate cancer diagnosis on metastasis of the shoulder which was treated with analgesic radiotherapy and chemo-hormonal therapy.

\section{Observation}

A 66-year-old patient, without any particular pathological history, was referred to our clinic for a mass of the right shoulder that has been evolving for 3 years and became painful for 1 year. The mechanical pain was relieved by taking nonsteroidal anti-inflammatory drugs. The physical examination revealed a $10 \mathrm{~cm}$ superior-posterior external mass of the right shoulder (Figure 1 \& Figure 2) with limitation of movements: arm raised forward limited to $45^{\circ}$, laterally to $60^{\circ}$. Biopsy of the mass and histological examination showed a moderately differentiated adenocarcinoma, Gleason $8(4+4)$. The thoracic abdominal and pelvic CT scan showed a mass of the shoulder (Figure 3 \& Figure 4), a mass of the prostate and pulmonary nodules (Figure 5). Total PSA was $508.52 \mathrm{ng} / \mathrm{ml}$ and creatinine was $9.92 \mathrm{mg} / \mathrm{ml}$. A bone scan was performed, showing disparate fixations in the spine in favor of bone metastasis. The multidisciplinary consultation recommended analgesic radiotherapy on the shoulder mass and chemotherapy in combination with ADT.

Radiotherapy consisted of a total dose of $30 \mathrm{~Gy}$ in 10 fractions to the shoulder with

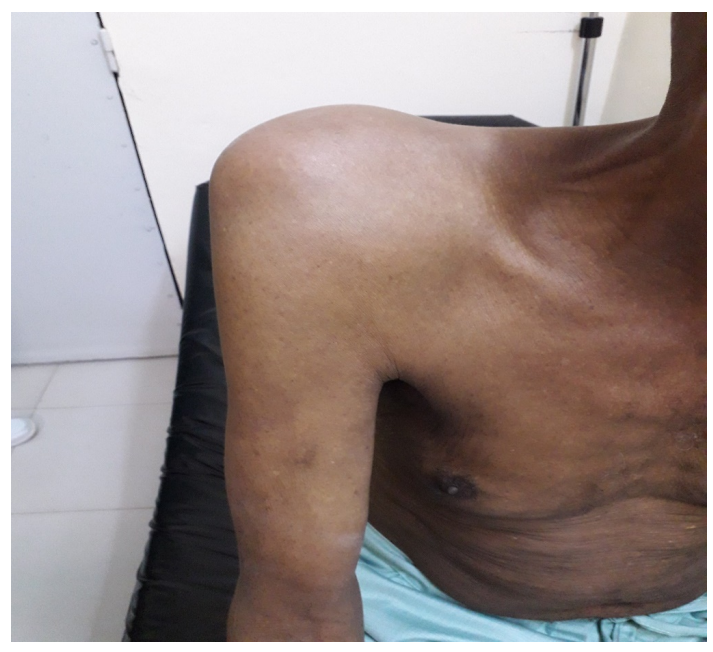

Figure 1. Metastatic mass of the right shoulder of prostate cancer (anterior view). 


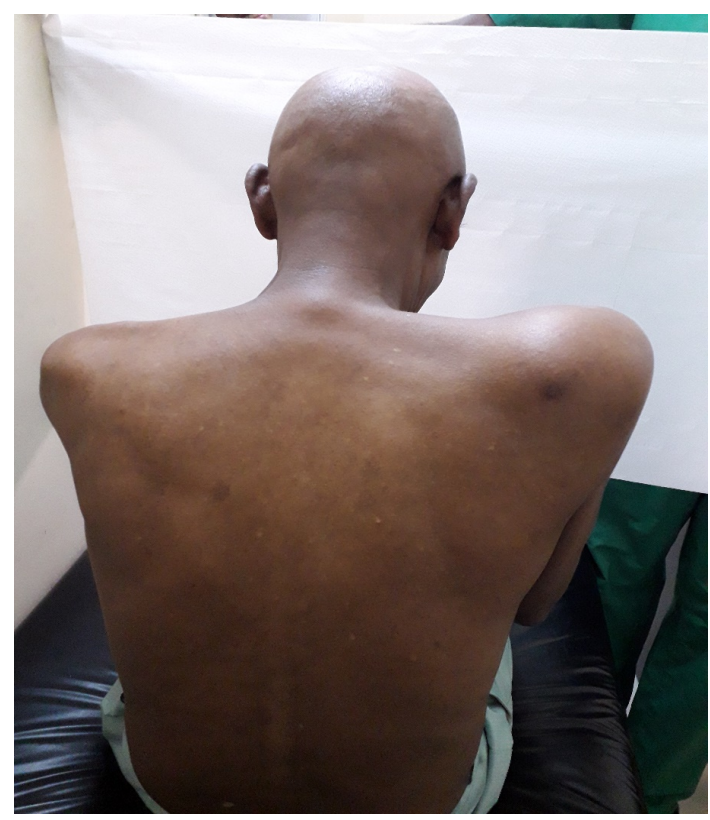

Figure 2. Metastatic mass of the right shoulder of prostate cancer (posterior view).

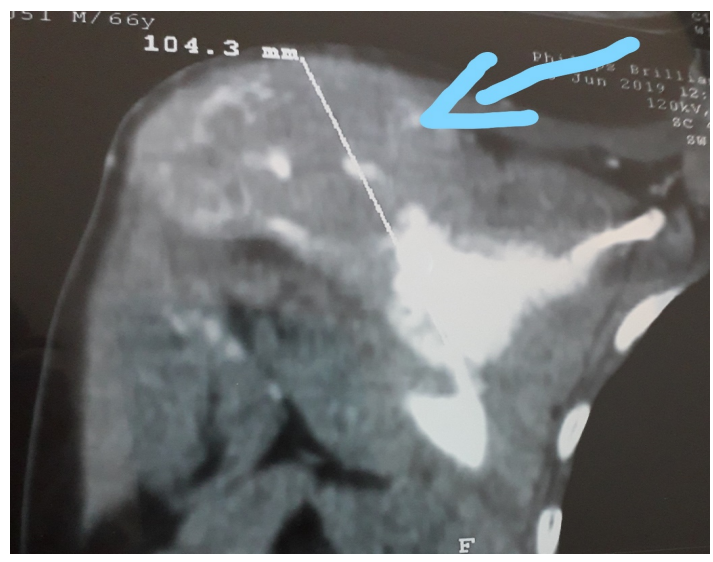

Figure 3. Coronal CT scan showing a metastatic mass in the right shoulder of prostate cancer.

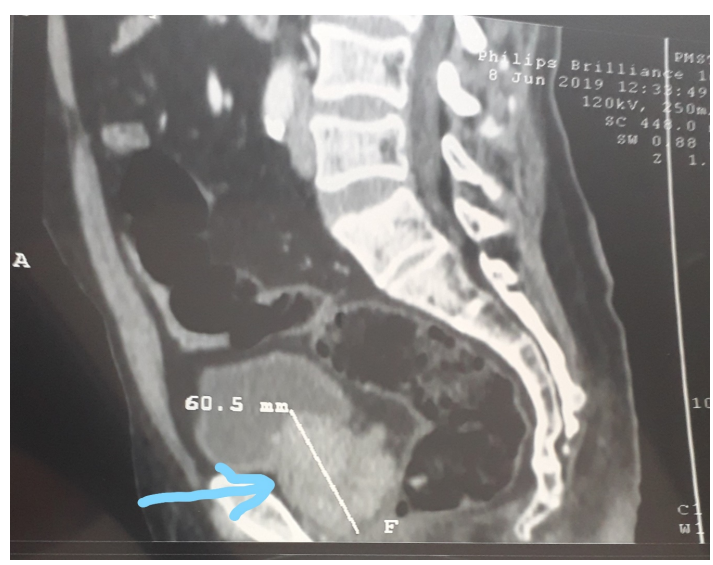

Figure 4. Sagittal CT scan showing a prostate mass. 


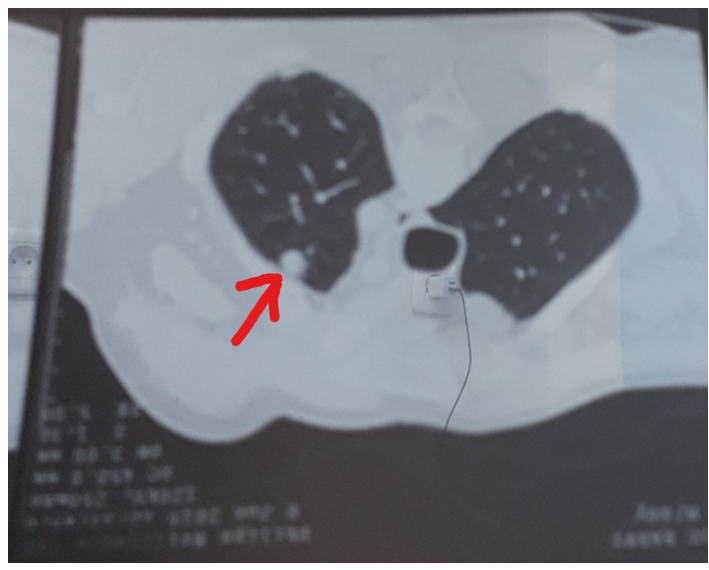

Figure 5. Axial CT scan showing a metastatic nodule in the lung of prostate cancer.

the total disappearance of mechanical pain and functional recovery of the shoulder. The patient received 6 cures of Docetaxel $60 \mathrm{mg} / \mathrm{m}^{2}$ with grade 2 alopecia without other toxicities, hormone therapy based on LH-RH analogue with grade 2 sexual dysfunction. At 2 years of follow-up, the mass regressed considerably and the PSA level returned to $5.25 \mathrm{ng} / \mathrm{ml}$.

\section{Discussion}

Near $4 \%$ of patients are found to be metastatic at the time of prostate cancer diagnosis [1]. These patients have a much more aggressive disease than the patients who progress with metachronous metastases. In these patients, the duration of hormone sensitivity and life expectancy are short [2]. Our patient was metastatic at the time of diagnosis.

The metastases preferentially target the bones and lymph nodes, but also the viscera such as the liver, lungs or brain [13]. In the bones, the pelvis and the spine were most often affected. The rare fact in our case was the revelation of cancer in his shoulder by a mass that could have been mistaken for a primary soft tissue and bone tumor. Indeed, although the bone and muscle are contiguous, their neoplastic invasion corresponds to different levels of progression and prognosis. The bone localization corresponds to an M1b type metastasis while the more advanced muscle localization corresponds to the M1c stage. Thus our patient did not have any urinary symptoms which would have made us look for a prostatic tumor.

Pain is not uncommon in metastatic prostate cancer, and it significantly affects the quality of life [9]. Apart from the analgesic drug, radiotherapy is an effective treatment that improves survival and quality of life [10] [11]. Different treatment regimens are used for three-dimensional pain relief radiotherapy. This includes the unfractionated 8 Gy scheme and the schemes 20 Gy in 5 fractions and $30 \mathrm{~Gy}$ in 10 fractions [14]. In our patient, the $30 \mathrm{~Gy}$ in 10 fractions scheme was used. It should be noted that many studies have shown the equivalence of unfractionated treatment in terms of pain relief compared to multi-fractionated 
treatments. Moreover, scientific societies and organizations recommend the unfractionated regimen [14] [15] [16]. Nevertheless, there is heterogeneity of prescriptions linked to the practice setting and the age of the provider. Nonfractionated treatment is much more widely used in the United States and Japan [17] [18]. In Europe too, prescriptions vary from country to country, but unfractionated treatment was prescribed by a third and half of providers [19]. The age of the provider is also decisive in the decision. The older the radiotherapist, the more likely he or she is to use a non-split regimen [20]. In our case, the provider was 28 years old.

A survey conducted in 2009 showed that the dose most recommended by the specialists interviewed was $30 \mathrm{~Gy}$ in ten fractions, or $20 \mathrm{~Gy}$ in five fractions [14].

In addition to symptomatic treatment, metastatic prostate cancer is treated with chemotherapy and ADT [5].

The principle of ADT is to reduce testosterone levels to below $50 \mathrm{ng} / \mathrm{ml}$. This strategy uses LH-RH agonists or antagonists [21]. The largest study and meta-analyses have shown an interest in the survival by using ADT, despite the discrepancy in the studies [22]. No benefit was found in terms of overall survival during the period of treatment (immediate or delayed) [16]. However, the immediate start of hormone therapy at the onset of symptoms can delay the onset of progression and complications. This has led to a consensus on the treatment of all cancers that are metastatic from the diagnosis [21].

This ADT is not sufficient for the treatment of metastatic cancers from the outset. Indeed, the CHAARTED and GETUG 15 meta-analyses show that the addition of docetaxel chemotherapy provides an overall survival benefit in patients with a large tumor volume [23]. The STAMPEDE retrospective analysis showed a comparable benefit whatever the tumor volume [24].

Our patient had a hormone therapy based on LH-RH analogue associated with 6 cures of docetaxel. At 2 years of follow-up, the shoulder mass regressed with a correct control of the PSA level.

\section{Conclusion}

The diagnosis of metastatic prostate cancer is not uncommon. However, the location on the shoulder is very rare. The multi-modal treatment shows a good response in our case. The local treatment of symptomatic metastasis by radiotherapy improves the quality of life.

\section{Conflicts of Interest}

The authors declare no conflicts of interest regarding the publication of this paper.

\section{References}

[1] Miller, K.D., Nogueira, L., Mariotto, A.B., Rowland, J.H., Yabroff, K.R., Alfano, C.M., et al. (2019) Cancer Treatment and Survivorship Statistics, CA: A Cancer Journal for Clinicians, 69, 363-385. https://doi.org/10.3322/caac.21565 
[2] Finianos, A., Gupta, K., Clark, B., Simmens, S.J. and Aragon-Ching, J.B. (2017) Characterization of Differences between Prostate Cancer Patients Presenting with De Novo Versus Primary Progressive Metastatic Disease. Clinical Genitourinary Cancer, 16, 85-89. https://doi.org/10.1016/j.clgc.2017.08.006

[3] Cooperberg, M.R., Lubeck, D.P., Meng, M.V., Mehta, S.S. and Carroll, P.R. (2004) The Changing Face of Low-Risk Prostate Cancer: Trends in Clinical Presentation and Primary Management. Journal of Clinical Oncology, 22, 2141-2149. https://doi.org/10.1200/JCO.2004.10.062

[4] Coleman, R.E. (2001) Metastatic Bone Disease: Clinical Features, Pathophysiology and Treatment Strategies. Cancer Treatment Reviews, 27, 165-176. https://doi.org/10.1053/ctrv.2000.0210

[5] Belderbos, B.P.S., de Wit, R., Lolkema, M.P.J., Mathijssen, R.H.J., van Soest, R.J. (2019) Novel Treatment Options in the Management of Metastatic Castration Naïve Prostate Cancer; Which Treatment Modality to Choose? Annals of Oncology, 30, 1591-1600. https://doi.org/10.1093/annonc/mdz210

[6] Culp, S.H., Schellhammer, P.F. and Williams, M.B. (2014) Might Men Diagnosed with Metastatic Prostate Cancer Benefit from Definitive Treatment of the Primary Tumor? A SEER-Based Study. European Urology, 65, 1058-1066. https://doi.org/10.1016/j.eururo.2013.11.012

[7] Rusthoven, C.G., Jones, B.L., Flaig, T.W., Crawford, E.D., Koshy, M., Sher, D.J., et al. (2016) Improved Survival with Prostate Radiation in Addition to Androgen Deprivation Therapy for Men with Newly Diagnosed Metastatic Prostate Cancer. Journal of Clinical Oncology, 34, 2835-2842. https://doi.org/10.1200/JCO.2016.67.4788

[8] Cho, Y., Chang, J.S., Rha, K.H., Hong, S.J., Choi, Y.D., Ham, W.S., et al. (2016) Does Radiotherapy for the Primary Tumor Benefit Prostate Cancer Patients with Distant Metastasisat Initial Diagnosis? PLoS ONE, 11, e0147191. https://doi.org/10.1371/journal.pone.0147191

[9] Papatheofanis, F.J., Williams, E. and Chang, S.D. (2009) Cost-Utility Analysis of the Cyberknife System for Metastatic Spinal Tumors. Neurosurgery, 64, 73-83. https://doi.org/10.1227/01.NEU.0000341205.37067.DE

[10] Chow, E., Wu, J.S.Y., Hoskin, P., Coia, L.R., Bentzen, S.M. and Blitzer, P.H. (2002) International Consensus on Palliative Radiotherapy Endpoints for Future Clinical trials in Bone Metastases. Radiotherapy and Oncology, 64, 275-280.

https://doi.org/10.1016/S0167-8140(02)00170-6

[11] Thureau, S., Vieillard, M.-H., Supiot, S. and Lagrange, J.-L. (2016) Radiothérapie des métastases osseuses. Cancer/Radiothérapie, 20, 227-234.

https://doi.org/10.1016/j.canrad.2016.07.027

[12] Maher, E.J., Coia, L., Duncan, G. and Lawton, P.A. (1992) Treatment Strategies in Advanced and Metastatic Cancer: Differences in Attitude between the USA, Canada and Europe. International Journal of Radiation Oncology, Biology, Physics, 23, 239244. https://doi.org/10.1016/0360-3016(92)90568-3

[13] Bastié, J.-P., et al. (2019) Points clés de l'annonce pour le cancer dela prostate métastatique. Progrès en Urologie, 29, 908-911.

https://doi.org/10.1016/j.purol.2019.10.001

[14] Lutz, S., Balboni, T., Jones, J., Lo, S., Petit, J., Rich, S.E., et al. (2017) Palliative Radiation Therapy For Bone Metastases: Update of an ASTRO Evidence-Based Guideline. Practical Radiation Oncology, 7, 4-12. https://doi.org/10.1016/j.prro.2016.08.001 
[15] International Atomic Energy Agency (2007) Criteria for Palliation of Bone Metastases-Clinical Applications. International Atomic Energy Agency, Vienna, Austria.

[16] Nair, B., Wilt, T., MacDonald, R. and Rutks, I. (2002) Early Versus Deferred Androgen Suppression in the Treatment of Advanced Prostatic Cancer. Cochrane Database of Systematic Reviews, 1, Article ID: CD003506.

https://doi.org/10.1002/14651858.CD003506

[17] van der Linden, Y., Roos, D., Lutz, S. and Fairchild, A. (2009) International Variations in Radiotherapy Fractionation for Bone Metastases: Geographic Borders Define Practice Patterns? Clinical Oncology, 21, 655-658. https://doi.org/10.1016/j.clon.2009.08.004

[18] Nakamura, N., Shikama, N., Wada, H., Harada, H., Nozaki, M., Nagakura, H., et al. (2012) Patterns of Practice in Palliative Radiotherapy for Painful Bone Metastases: A Survey in Japan. International Journal of Radiation Oncology, Biology, Physics, 83, 117-120. https://doi.org/10.1016/j.ijrobp.2011.11.075

[19] Lievens, Y., Dunscombe, P., Defourny, N., Gasparotto, C., Borras, J.M. and Grau, C. (2015) HERO (Health Economics in Radiation Oncology): A Pan-European Project on Radiotherapy Resources and Needs. Clinical Oncology, 27, 115-124.

https://doi.org/10.1016/j.clon.2014.10.010

[20] Bradley, N.M.E., Husted, J., Sey, M.S.L., Sinclair, E., Li, K.K., Husain, A.F., et al. (2008) Didthe Pattern of Practice in the Prescription of Palliative Radiotherapy for the Treatment of Uncomplicated Bone Metastases Change between 1999 and 2005 at the Rapid Response Radiotherapy Program? Clinical Oncology, 20, 327-336. https://doi.org/10.1016/j.clon.2008.01.002

[21] Rozet, F., et al. (2020) Recommandations franc, aises du comité de cancérologie de l'AFU pour le cancer de la prostate: Cancer de prostate métastatique HormonoSensible-Actualisation 2020. Progrès en Urologie, 30, 430-438. https://doi.org/10.1016/j.purol.2020.04.017

[22] Prostate Cancer Trialists Collaborative Group (2000) Maximum Androgen Blockade in Advanced Prostate Cancer: An Overview of the Randomised Trials. Lancet, 355, 1491-1498. https://doi.org/10.1016/S0140-6736(00)02163-2

[23] Kyriakopoulos, C.E., Chen, Y.H., Carducci, M.A., Liu, G., Jarrard, D.F., Hahn, N.M., et al. (2018) Chemohormonal Therapy in Metastatic Hormone-Sensitive Prostate Cancer: Long-Term Survival Analysis of the Randomized Phase III E3805 CHAARTED Trial. Journal of Clinical Oncology, 36, 1080-1087. https://doi.org/10.1200/JCO.2017.75.3657

[24] Clarke, N.W., Ali, A., Ingleby, F.C., Hoyle, A., Amos, C.L., Attard, G., et al. (2019) Addition of Docetaxel to Hormonal Therapy in Low- and High-Burden Metastatic Hormone Sensitive Prostate Cancer: Long-Term Survival Results from the Stampede Trial. Annals of Oncology, 30, 1992-2003. https://doi.org/10.1093/annonc/mdz248.001 